\title{
The Completeness Theorems for Some Intuitionistic Epistemic Logics in Terms of Interval Semantics
}

By

\author{
Michiro KONDO*
}

\section{Introduction}

So far, "normal" modal logics are considered in many papers. In these logics the rule of necessitation (if $\vdash \mathrm{A}$, then $\vdash \square \mathrm{A}$ ) is permitted. Philosophically speaking, it means that what is assertoric is what is necessary. For example, if it rains today, then it necessarily rains. But it seems that this necessitarian world view is different from our ordinary one. Hence in order to consider modal logics which are akin to our world view, we had better do the non-normal modal logics.

To begin with, we take the intuitionistic logic as a basic logic, and we will consider the non-normal modal logics on it. Moreover we will evaluate the modal formulas in terms of interval semantics mentioned below.

It seems that this procedure gives rather weak modal logics and that they are akin to our ordinary world view. Mathematically speaking, to consider the epistemic logics on the intuitionistic logic corresponds to this procedure. So, in this paper, we will consider the intuitionistic epistemic systems, in which no formulas of the form $\square \mathrm{A}$ are provable. Trying to develop semantics for these systems, a complication arises. Every formula of the form $\square \mathrm{A}$ is not provable in these systems. Especially $\square$ ( $p \rightarrow p$ ) is not valid if we could have the completeness theorems in our semantics. But in usual semantics for modal logic, $\square \mathrm{A}$ is said to be true at a world $\mathrm{x}$ in $\mathrm{W}$ if and only if $A$ is true at every world $y$ in $W$ such that $x R y$. Accordingly, if

Communicated by S. Takasu, June 21, 1983. Revised September 8, 1983.

* Depariment of Mathematics, Rikkyo University, Nishi-ikebukuro, Tokyo 171, Japan. 
$\square(\mathrm{p} \rightarrow \mathrm{p})$ is not valid in this semantics, then $\mathrm{p} \rightarrow \mathrm{p}$ is not valid at some world. However $\mathrm{p} \rightarrow \mathrm{p}$ is a tautology, it must be true at every world. In order to overcome this difficulty, S. A. Kripke has developed a new model structure in [7], which includes one more set whose every member called normal. Namely he divided the set of worlds into two disjoint subsets of normal and non-normal worlds.

Further in [6] he has considered the intuitionistic logic and its semantics with the idea of a model structure.

Recently, I. L. Humberstone ([5]) and P. Röper ([8]) have developed a different semantics, called "interval semantics", from Kripke's one essentially, although these structures are alike. In this semantics the truth of a formula is evaluated not at a moment but at an interval. For example, if a formula $A$ is true at an interval $x$, then it is true at every subinterval of $x$.

In this paper, we will show the completeness theorems for some intuitionistic epistemic logics (IE, IE2, IE3, IET, and IE4) in terms of interval semantics which is a fusion of Kripke's non-normal and intuitionistic structures. L. F. Goble has studied these logics in [3], but he used an axiom $\square \mathrm{A} \vee \neg \square \mathrm{A}$, which is somewhat unfaithful to the spirit of the intuitionistic enterprise. Here we do not use this axiom.

Further, we refer to the decidabilities of these systems.

\section{§1. Formal Systems and Semantics}

It is supposed that these systems (IE, IE2, IE3, IET, and IE4) are expressed in a language with propositional variables $p, q, r$, etc., the usual truth-functional connectives $\wedge$ (conjunction), $\vee$ (disjunction), $\rightarrow$ (implication), $\neg$ (negation), and the modal operator $\square$ (necessity), governed by the usual grammatical rules. Since we are working with intuitionistic systems, we suppose that $\Lambda, \vee, \rightarrow, \neg$, and $\square$ are the primitive connectives. Letters A, B, C, etc. are used as variables for well-formed formulas.

The systems are generated from among the following axiom schemata:

A.0 axioms which are adequate for the intuitionistic propositional logic

A.1 $\square(\mathrm{A} \rightarrow \mathrm{B}) \rightarrow(\square \mathrm{A} \rightarrow \square \mathrm{B})$ 
A.2 $\square \mathrm{A} \rightarrow \mathrm{A}$

A.3 $\square(\mathrm{A} \rightarrow \mathrm{B}) \rightarrow \square(\square \mathrm{A} \rightarrow \square \mathrm{B})$

A.4 $\square \mathrm{T} \rightarrow \square \square \mathrm{T}$, where $\mathrm{T}$ is some designated tautology such as $\mathrm{p} \rightarrow \mathrm{p}$,

and the rule schemata:

R.1 modus ponens

$\mathrm{R} .2$ if $\vdash \mathrm{A} \rightarrow \mathrm{B}$, then $\vdash \square \mathrm{A} \rightarrow \square \mathrm{B}$.

The system IE is defined by A.0, A.1, R.1, and R.2. IE2 is the result of adding A.2 to IE; IE3 is the result of adding A.3 to IE2; IET is the result of adding A.4 to IE2; and IE4 is the result of adding A.4 to IE3.

The structure $\langle\mathrm{W}, \mathrm{N}, \subseteq, \mathrm{R}\rangle$ is called a frame, where $\mathrm{W}$ is a nonempty set, $\mathrm{N}$ is a subset of $\mathrm{W}, \subseteq$ is a reflexive and transitive relation on $W$ satisfying the property: if $x \in N$ and $y \subseteq x$ then $y \in N$, and $R$ is also a relation on $\mathrm{W}$ satisfying the following property: persistent for future i.e. if $x R y$ and $z \subseteq y$ then $x R z$. Every element of $N$ is called normal.

Let $\mathrm{P}$ be a set of propositional variables and $\mathrm{V}$ be a function from $\mathrm{P} \times \mathrm{W}$ to the set of truth-values $\{0,1\}$ such that $\mathrm{V}(\mathrm{p}, \mathrm{x})=1$ and $\mathrm{y} \subseteq \mathrm{x}$ imply $\mathrm{V}(\mathrm{p}, \mathrm{y})=1$. Then the structure $\langle\mathrm{W}, \mathrm{N}, \subseteq, \mathrm{R}, \mathrm{V}\rangle$ is called a model on the frame $\langle\mathrm{W}, \mathrm{N}, \subseteq, \mathrm{R}\rangle$. By adding further conditions to the frame we obtain some models corresponding to these systems.

We now define the truth of a formula $A$ at $x \in W$ in a model $\mathfrak{M}=\langle\mathrm{W}, \mathrm{N}, \subseteq, \mathrm{R}, \mathrm{V}\rangle$ by recursive definition on the length of $\mathrm{A}$ as follows :

(1) $\quad \mathfrak{M} \vDash F_{\mathrm{x}} \mathrm{p} \quad$ iff $\mathrm{V}(\mathrm{p}, \mathrm{x})=1$

(2) $\quad \mathfrak{M} \vDash \vDash_{\mathrm{x}} \neg \mathrm{A} \quad$ iff for every y such that $\mathrm{y} \subseteq \mathrm{x}$

not $\mathfrak{M} F_{\mathrm{y}} \mathrm{A}\left(\mathfrak{M}_{F_{\mathrm{y}}} \mathrm{A}\right)$

( 3 ) $\mathfrak{M}_{{ }_{\mathrm{x}}} \mathrm{A} \wedge \mathrm{B}$ iff $\mathfrak{M} \vDash_{{ }_{\mathrm{x}}} \mathrm{A}$ and $\mathfrak{M}_{\models_{\mathrm{x}} \mathrm{B}}$

(4) $\mathfrak{M} \vDash_{x} \mathrm{~A} \vee \mathrm{B}$ iff $\mathfrak{M} \models_{{ }_{\mathrm{x}} \mathrm{A}}$ or $\mathfrak{M} \models_{{ }_{\mathrm{x}} \mathrm{B}}$

( 5 ) $\mathfrak{M} \models_{{ }_{x}} A \rightarrow B$ iff for every $y \subseteq x$ if $\mathfrak{M} \models_{y} A$ then $\mathfrak{M} \models_{y} B$

(6) $\quad \mathfrak{M} F_{\mathrm{x}} \square \mathrm{A} \quad$ iff $\mathrm{x} \in \mathrm{N}$ and for every $\mathrm{y} \subseteq \mathrm{x}$ and $\mathrm{z}$ such that $\mathrm{yRz}, \quad \mathfrak{M} \vDash_{z} \mathrm{~A}$.

When $\mathfrak{M}_{{ }_{\lambda}} \mathrm{A}$, we say that $\mathrm{A}$ is true at $\mathrm{x}$ in a model $\mathfrak{M}$. $\mathrm{A}$ is said to be valid when $A$ is true at any $x \in W$ for every model 
$\mathfrak{M}=\langle\mathrm{W}, \mathrm{N}, \subseteq, \mathrm{R}, \mathrm{V}\rangle$.

Let $\mathrm{L}$ be one of systems of IE, IE2, IE3, IET, and IE4. We list the frame conditions of these systems:

(IE2) $\mathrm{R}$ is reflexive on $\mathrm{N}$

(IE3) if $x R y, y R z$, and $y \in N$, then $x R z$

(IET) if $x \in N$ and $x R y$, then $y \in N$

(IE4) (IE3) and (IET).

Now we define L-frame: when $\mathrm{L}$ is $\mathrm{IE}$, an IE-frame is the same one as defined above. An IE2 (IE3, IET, IE4)-frame is a frame with the condition (IE2) ((IE3), (IET), (IE4)). An L-model means a model on an L-frame.

Our first main theorem is that $\mathrm{A}$ is provable in $\mathrm{L}$ if and only if $A$ is $L$-valid, where we say that $A$ is $L$-valid when $A$ is true at any element of every L-model. We will show this in the next section.

\section{§ 2. Completeness of IE}

First we mention the soundness part. Here we consider only IE, so $\mathrm{L}$ means IE.

Theorem 1. If $\vdash_{\mathrm{L}} \mathrm{A}$, then $\mathrm{A}$ is $\mathrm{L}$-valid.

Proof. We have to show that the axioms of $L$ are valid and that rules preserve the validity. We only show that R.2 preserves the validity.

Suppose that $\mathrm{A} \rightarrow \mathrm{B}$ is $\mathrm{L}$-valid but $\square \mathrm{A} \rightarrow \square \mathrm{B}$ is not. There is a counter model $\mathfrak{M}=\langle\mathrm{W}, \mathrm{N}, \subseteq \mathrm{R}, \mathrm{V}\rangle$ for $\square \mathrm{A} \rightarrow \square \mathrm{B}$ and $\mathrm{x} \in \mathrm{W}$ such that $\mathfrak{M} \not F_{\mathrm{x}} \square \mathrm{A} \rightarrow \square \mathrm{B}$. Then there is a $\mathrm{y} \subseteq \mathrm{x}$ such that $\mathfrak{M} \vdash_{\mathrm{y}} \square \mathrm{A}$ and $\mathfrak{M} \not F_{\mathrm{y}} \square \mathrm{B}$ by truth definition. Since $\mathrm{y} \in \mathrm{N}$, there are $\mathrm{z} \subseteq \mathrm{y}$ and $\mathrm{u}$ such that $\mathrm{zRu}$ and $\mathfrak{M} \models_{{ }_{\mathrm{u}}} \mathrm{B}$. By $\mathfrak{M} \models_{\mathrm{y}} \square \mathrm{A}$, we have $\mathfrak{M} \models_{\mathrm{u}} \mathrm{A}$ and $\mathfrak{M} \nvdash_{{ }_{\mathrm{u}}} \mathrm{A} \rightarrow$ B. But this implies that $\mathrm{A} \rightarrow \mathrm{B}$ is not true at $\mathrm{u}$ in $\mathfrak{M}$, so $\mathrm{A} \rightarrow \mathrm{B}$ is not valid. This contradicts the assumption. Therefore the rule R.2 preserves the validity.

Next we have to show the completeness part, but before doing so we prepare some definitions and lemmas.

By a theory we mean a set of formulas in L. A theory $\Delta$ is called a saturated theory when it satisfies the next conditions: 
(1) $\Delta \ni \mathrm{A} \wedge \mathrm{B}$ implies $\Delta \ni \mathrm{A}$ and $\Delta \ni \mathrm{B}$

(2) $\Delta \ni \mathrm{A} \vee \mathrm{B}$ implies $\Delta \ni \mathrm{A}$ or $\Delta \ni \mathrm{B}$

(3) $\Delta \vdash \mathrm{A}$ implies $\Delta \ni \mathrm{A}$

(4) $\Delta$ is consistent.

It is easy to show that any saturated theory $\Delta$ is closed under R.1: if $\Delta \ni \mathrm{A}$ and $\Delta \ni \mathrm{A} \rightarrow \mathrm{B}$, then $\Delta \ni \mathrm{B}$.

We have a powerful method for showing the completeness theorem. By a canonical model for $\mathrm{L}$, we mean a structure $\left\langle\mathrm{W}_{\mathrm{L}}, \mathrm{N}_{\mathrm{L}}, \subseteq_{\mathrm{L}}, \mathrm{R}_{\mathrm{L}}\right.$, $V_{L}>$ where $W_{L}$ is the set of all saturated theories of $L, N_{L}$ is the subset of $\mathrm{W}_{\mathrm{L}}$ whose every member has at least a sort of formula $\square \mathrm{A}$ for some A.

For any $\mathrm{x}, \mathrm{y} \in \mathrm{W}_{\mathrm{L}}$, we define $\subseteq_{\mathrm{L}}, \mathrm{R}_{\mathrm{L}}$, and $\mathrm{V}_{\mathrm{L}}$ as follows:

(i) $y \subseteq_{L} x$ iff $x$ is a subset of $y$

(ii) $\quad \mathrm{xR}_{\mathrm{L}} \mathrm{y} \quad$ iff $\quad\{\mathrm{B} \mid \mathrm{x} \vdash \square(\mathrm{p} \rightarrow \mathrm{p}) \rightarrow \square \mathrm{B}\} \subset \mathrm{y}$

(iii) $\mathrm{V}_{\mathrm{L}}(\mathrm{p}, \mathrm{x})=1$ iff $\mathrm{p} \in \mathrm{x}$.

Then the canonical model $\mathfrak{M}_{\mathrm{L}}=\left\langle\mathrm{W}_{\mathrm{L}}, \mathrm{N}_{\mathrm{L}}, \subseteq_{\mathrm{L}}, \mathrm{R}_{\mathrm{L}}, \mathrm{V}_{\mathrm{L}}\right\rangle$ becomes a model in our semantics.

(1) $\mathrm{N}_{\mathrm{L}}$ is a subset of $\mathrm{W}_{\mathrm{L}}$

and

(2) $\subseteq_{\mathrm{L}}$ is a reflexive and transitive on $\mathrm{W}_{\mathrm{L}}$

are evident.

(3) $\mathrm{x} \in \mathrm{N}_{\mathrm{L}}$ and $\mathrm{y} \subseteq_{\mathrm{L}} \mathrm{x}$ imply $\mathrm{y} \in \mathrm{N}_{\mathrm{L}}$ :

Suppose that $\mathrm{x} \in \mathrm{N}_{\mathrm{L}}$ and $\mathrm{y} \subseteq_{\mathrm{L}} \mathrm{x}$. There is a formula $\mathrm{A}$ such that $\square \mathrm{A} \in \mathrm{x}$. Since $\mathrm{y} \subseteq_{\mathrm{L}} \mathrm{x}, \square \mathrm{A} \in \mathrm{y}$, so $\mathrm{y} \in \mathrm{N}_{\mathrm{L}}$.

(4) $R_{L}$ is persistent for future :

Suppose that $x R_{L} y$ and $z \subseteq_{L} y$. Let us assume that $x \vdash \square(p \rightarrow p)$ $\rightarrow \square$ B. From the definition of $R_{L} B \in y$. Since $z \subseteq_{L} y, B \in z$. This means that $\{\mathrm{B} \mid \mathrm{x} \vdash \square(\mathrm{p} \rightarrow \mathrm{p}) \rightarrow \square \mathrm{B}\} \subset \mathrm{z}$ and $\mathrm{xR}_{\mathrm{L}} \mathrm{z}$.

(5) $\mathrm{V}_{\mathrm{L}}(\mathrm{p}, \mathrm{x})=1$ and $\mathrm{y} \subseteq_{\mathrm{L}} \mathrm{x}$ imply $\mathrm{V}_{\mathrm{L}}(\mathrm{p}, \mathrm{y})=1$ :

It is easy to show this condition.

Hence the canonical model $\mathfrak{M}_{\mathrm{L}}=\left\langle\mathrm{W}_{\mathrm{L}}, \mathrm{N}_{\mathrm{L}}, \subseteq_{\mathrm{L}}, \mathrm{R}_{\mathrm{L}}, \mathrm{V}_{\mathrm{L}}\right\rangle$ is indeed a model in our semantics.

We show the fundamental properties with respect to the canonical model. They are useful to show the completeness part. 
Lemma 2. If $\Delta \forall \mathrm{A}$, then there exists a saturated theory $\mathrm{x}$ such that $\mathrm{x} \supset \Delta$ and $\mathrm{x} \nsubseteq \mathrm{A}$.

Proof. See Thomason [9].

Lemma 3. For any normal saturated theory $\mathrm{x}$, if $\mathrm{x} \forall \square \mathrm{A}$, then there exists a saturated theory $\mathrm{y}$ such that $\mathrm{xR}_{\mathrm{L}} \mathrm{y}$ and $\mathrm{y} \neq \mathrm{A}$.

Proof. See Gabbay [2].

Lemma 4. If $\Delta \vdash \square \mathrm{B}$ for some $\mathrm{B}$, then $\Delta \vdash \square(\mathrm{p} \rightarrow \mathrm{p})$.

Proof. Suppose $\Delta \vdash \square \mathrm{B}$ for some B. Since $\vdash \mathrm{B} \rightarrow(\mathrm{p} \rightarrow \mathrm{p})$, $\Delta \vdash \square \mathrm{B} \rightarrow \square(\mathrm{p} \rightarrow \mathrm{p})$. Thus we have $\Delta \vdash \square(\mathrm{p} \rightarrow \mathrm{p})$.

Lemma 5. Let $\mathfrak{M}_{\mathrm{L}}=\left\langle\mathrm{W}_{\mathrm{L}}, \mathrm{N}_{\mathrm{L}}, \subseteq_{\mathrm{L}}, \mathrm{R}_{\mathrm{L}}, \mathrm{V}_{\mathrm{L}}\right\rangle$ be a canonical model for $\mathrm{L}$. Then for every $\mathrm{x} \in \mathrm{W}_{\mathrm{L}}$ and formula $\mathrm{A}$ of $\mathrm{L}$,

$$
\mathfrak{M}_{\mathrm{L}} \vDash{ }_{\mathrm{x}} \mathrm{A} \quad \text { iff } \mathrm{A} \in \mathrm{x} \text {. }
$$

Proof. (by induction on the length of $\mathrm{A}$ )

We only show the cases of $\neg \mathrm{B}$ and of $\square \mathrm{B}$.

For $\neg \mathrm{B}$, suppose that $\mathfrak{M}_{\mathrm{L}} \models \mathrm{x} \neg \mathrm{B}$ but $\neg \mathrm{B} \notin \mathrm{x}$. Then $\mathbf{x} \not \forall \neg \mathrm{B}$, i. e. $\mathrm{x} \cup\{\mathrm{B}\}$ is consistent. There is a saturated theory $\mathrm{y}$ such that $\mathrm{y} \supset \mathrm{x} \cup\{\mathrm{B}\}$ by lemma 2. Clearly $\mathrm{y} \subseteq_{\mathrm{L}} \mathrm{x}$ and $\mathrm{B} \in \mathrm{y}$. When $\mathrm{y} \subseteq_{\mathrm{L}} \mathrm{x}$, the assumption and I. H. (induction hypothesis) yield $\mathrm{B} \notin \mathrm{y}$. This contradicts the fact that $\mathrm{B} \in \mathrm{y}$. Therefore $\neg \mathrm{B} \in \mathrm{x}$.

Conversely, suppose $\neg \mathrm{B} \in \mathrm{x}$. For every y such that $\mathrm{y} \subseteq_{\mathrm{L}} \mathrm{x}$, we have $\neg \mathrm{B} \in \mathrm{y}$. Since $\mathrm{y}$ is consistent, $\mathrm{B} \notin \mathrm{y}$. This yields $\mathfrak{M}_{\mathrm{L}} \vDash_{\mathrm{x}} \neg \mathrm{B}$.

For $\square \mathrm{B}$, suppose that $\mathfrak{M}_{\mathrm{L}} \vDash_{\mathrm{x}} \square \mathrm{B}$ but $\square \mathrm{B} \notin \mathrm{x}$. Since $\mathrm{x}$ is normal, there is a formula $\mathrm{C}$ such that $\square \mathrm{C} \in \mathrm{x}$. By lemma 4 we have $\{\mathrm{D} \mid \mathrm{x} \vdash \square(\mathrm{p} \rightarrow \mathrm{p}) \rightarrow \square \mathrm{D}\}=\{\mathrm{D} \mid \mathrm{x} \vdash \square \mathrm{D}\}$. Let $\mathrm{y}$ be $\{\mathrm{D} \mid \mathrm{x} \vdash \square \mathrm{D}\}$. Simple calculus and the rule R.2 yield y $\forall$ B. From lemma 2, there is a saturated theory $u$ such that $u \supset y$ but $u \neq B$. Clearly $x R_{L} u$. This implies $\mathfrak{M}_{\mathrm{L}} \not \neq_{\mathrm{x}} \square \mathrm{B}$, and it contradicts our assumption.

Conversely, suppose $\square \mathrm{B} \in \mathrm{x}$. It is clear that $\mathrm{x} \in \mathrm{N}_{\mathrm{L}}$ and $\square \mathrm{B} \in \mathrm{y}$ for every $\mathrm{y}$ and $\mathrm{z}$ such that $\mathrm{y} \subseteq_{\mathrm{L}} \mathrm{x}$ and $\mathrm{y} \mathrm{R}_{\mathrm{L}} \mathrm{z}$. This indicates $\mathrm{B} \in \mathrm{z}$. 
So $\mathfrak{M}_{\mathrm{L}} \vdash \mathrm{x} \square$ B.

This fundamental lemma has completely proved.

We are going to show the completeness theorem for $\mathrm{L}$. If $H_{\mathrm{L}} \mathrm{A}$, then there exists a saturated theory $\mathrm{x}$ such that $\mathrm{x} \nexists \mathrm{A}$ by lemma 2 . By lemma $5, \mathfrak{M}_{\mathrm{L}} \not{ }_{\mathrm{x}} \mathrm{A}$. That is, A is not $\mathrm{L}$-valid.

\section{§3. Completeness of Other Systems}

In this section, we will prove the completeness theorems for IE2 (IE3, IET, IE4) by use of the method mentioned in §2. Let IE2 (IE3, IET, IE4)-model be the model with the condition (IE2) ((IE3), (IET), (IE4)). Using these conditions, we can prove the completeness theorems for these systems respectively. Since the soundness parts can be proved easily, we only consider the completeness parts. For IE2 (IE3, IET, IE4) it is sufficient to show that the further condition (IE2) ((IE3), (IET), (IE4)) is satisfied by the canonical model for IE2 (IE3, IET, IE4).

For IE2, suppose $x \in N_{L}$. Since there is a formula $B$ such that $\square \mathrm{B} \in \mathrm{x}, \mathrm{x} \vdash \square(\mathrm{p} \rightarrow \mathrm{p})$ by lemma 4. Take any formula $\mathrm{A}$ such that $\mathrm{x} \vdash \square(\mathrm{p} \rightarrow \mathrm{p}) \rightarrow \square \mathrm{A}$. The axiom schema A.2 and the fact that $\mathrm{x} \vdash \square(\mathrm{p} \rightarrow \mathrm{p})$ yield $\mathrm{x} \vdash \mathrm{A}$. Hence $\mathrm{R}_{\mathrm{L}}$ is reflexive on $\mathrm{N}_{\mathrm{L}}$.

The proof of the completeness theorem for IE2 is carried out easily.

For IE3, suppose that $x R_{L} y, y R_{L} z$, and $y \in N_{L}$. Let $A$ be any formula such that $\mathrm{x} \vdash \square(\mathrm{p} \rightarrow \mathrm{p}) \rightarrow \square \mathrm{A}$. The axiom schema A.3 yields $\vdash \square \mathrm{A} \rightarrow \square(\square(\mathrm{p} \rightarrow \mathrm{p}) \rightarrow \square \mathrm{A})$ and $\mathrm{x} \vdash \square(\mathrm{p} \rightarrow \mathrm{p}) \rightarrow \square(\square(\mathrm{p} \rightarrow \mathrm{p}) \rightarrow \square \mathrm{A})$. Since $x R_{L} y$ and $y R_{L} z, y \vdash \square(p \rightarrow p) \rightarrow \square A$ and $z \vdash A$ i.e. $z \ni A$. We have $\{\mathrm{A} \mid \mathrm{x} \vdash \square(\mathrm{p} \rightarrow \mathrm{p}) \rightarrow \square \mathrm{A}\} \subset \mathrm{z}$. This means $\mathrm{xR}_{\mathrm{L}} \mathrm{z}$.

Therefore the completeness theorem for IE3 can be proved similarly.

For IET, it can be proved that the further condition (IET) is satisfied by the canonical model for IET. The condition means that $x \in N_{L}$ and $x R_{L} y$ imply $y \in N_{L}$.

Suppose that $x \in N_{L}$ and $x R_{L} y$. We have $x \vdash \square(p \rightarrow p) \rightarrow \square \square(p \rightarrow p)$ by the axiom schema A.4. By simple calculus we have $\square(\mathrm{p} \rightarrow \mathrm{p}) \in \mathrm{y}$ and $y \in N_{L}$.

The completeness theorem for IET holds.

We can prove the completeness theorem for IE4 similarly. 
In the next section, we will show that IE (IE2, IET, IE4) has the finite model property. We use the method called "filtration".

\section{§4. Filtration Method}

We apply the filtration method to any IE-model, which is a basic argument of our consideration.

Let $\mathfrak{M}=\langle\mathrm{W}, \mathrm{N}, \subseteq, \mathrm{R}, \mathrm{V}\rangle$ be an IE-model, and $\Phi$ be the set of formulas closed under subformulas. We define a filtration model $\mathfrak{M}^{*}$ of $\mathfrak{M}$ through $\Phi$.

For every $\mathrm{x}, \mathrm{y} \in \mathrm{W}$, we define $\mathrm{x} \equiv \mathrm{y}$ when $\mathfrak{M} \vDash{ }_{\mathrm{x}} \mathrm{A}$ iff $\mathfrak{M} \vDash{ }_{\mathrm{y}} \mathrm{A}$ for every formula $\mathrm{A}$ in $\Phi$.

$$
[\mathrm{x}]=\{\mathrm{y} \in \mathrm{W} \mid \mathrm{x} \equiv \mathrm{y}\}
$$

is an equivalence class of $\mathrm{x}$ under $\equiv$, and we set

$$
\mathrm{W}^{*}=\{[\mathrm{x}] \mid \mathrm{x} \in \mathrm{W}\} \text {. }
$$

For any $[\mathrm{x}],[\mathrm{y}] \in \mathrm{W}^{*}$, we define $\mathrm{N}^{*}, \subseteq^{*}, \mathrm{R}^{*}$, and $\mathrm{V}^{*}$ one by one.

$\mathrm{N}^{*} \ni[\mathrm{x}] \quad$ iff $\mathfrak{M} \models \times \mathrm{A}$ for some $\square \mathrm{A} \in \Phi$

$[\mathrm{y}] \subseteq{ }^{*}[\mathrm{x}] \quad$ iff if $\mathfrak{M} \vDash{ }_{\mathrm{x}} \mathrm{A}$ then $\mathfrak{M} \vDash{ }_{\mathrm{y}} \mathrm{A}$ for every formula $\mathrm{A} \in \Phi$

$[\mathrm{x}] \mathrm{R}^{*}[\mathrm{y}] \quad$ iff if $\mathfrak{M} \models_{\mathrm{x}} \square \mathrm{A}$ then $\mathfrak{M} \models_{\mathrm{y}} \mathrm{A}$ for every formula of the form $\square \mathrm{A} \in \Phi$,

and for every $\mathrm{p} \in \Phi$,

$$
\mathrm{V}^{*}(\mathrm{p},[\mathrm{x}])=1 \quad \text { iff } \mathrm{V}(\mathrm{p}, \mathrm{x})=1 \text {. }
$$

Let $\mathfrak{M}^{*}$ be the structure $\left\langle\mathrm{W}^{*}, \mathrm{~N}^{*}, \subseteq \subseteq^{*}, \mathrm{R}^{*}, \mathrm{~V}^{*}\right\rangle$, which is called a filtration of $\mathfrak{M}$ through $\Phi$.

It is evident that these definitions are well-defined. Clearly these definitions indicate that $\mathfrak{M}^{*}$ is indeed a model for IE.

We mention an interesting fact, which reflects the adequency of interval semantics.

Lemma 6. Let L be one of systems among IE, IE2, IE3, IET, and IE4. Let $\mathfrak{M}$ be a model corresponding to that system L. For every formula $\mathrm{A}$ and $\mathrm{x} \in \mathrm{W}$, if $\mathfrak{M} \vDash_{\mathrm{x}} \mathrm{A}$ and $\mathrm{y} \subseteq \mathrm{x}$, then $\mathfrak{M} \vDash_{\mathrm{r}} \mathrm{A}$.

Proof. It can be proved easily by induction on the length of A. 


\section{§5. Decidabilities}

We will show that IE (IE2, IET, IE4) has the finite model property. In order to do so, we need the next lemma.

Lemma 7. Let $\mathfrak{M}$ be an IE-model. For every $\mathrm{x} \in \mathrm{W}$ and formula $\mathrm{A} \in \Phi$,

$$
\mathfrak{M} * \vDash_{[\mathrm{x}]} \mathrm{A} \quad \text { iff } \mathfrak{M} \vDash_{\mathrm{x}} \mathrm{A} .
$$

Proof. (by induction on the length of A)

We only consider the cases of $\neg \mathrm{A}$ and of $\square \mathrm{A}$.

For $\neg \mathrm{A}$, suppose that $\mathfrak{M}^{*} \vDash_{[\mathrm{x}]} \neg \mathrm{A}$ but $\mathfrak{M}_{F_{\mathrm{x}}} \neg \mathrm{A}$. There is a y such that $\mathrm{y} \subseteq \mathrm{x}$ and $\mathfrak{M} \vDash_{\mathrm{y}} \mathrm{A}$. Since $\mathrm{y} \subseteq \mathrm{x}$, by lemma 6 we have $[\mathrm{y}] \subseteq^{*}[\mathrm{x}]$ and $\mathfrak{M}^{*} \vDash_{[y]} \mathrm{A}$. Thus we have $\mathfrak{M}^{*} F_{[x]} \neg \mathrm{A}$. But this is a contradiction.

Conversely, suppose that $\mathfrak{M}_{F_{\mathrm{x}}} \neg \mathrm{A}$ but $\mathfrak{M}^{*} \|_{[\times]} \neg \mathrm{A}$. There is a [y] such that $[\mathrm{y}] \subseteq^{*}[\mathrm{x}]$ and $\mathfrak{M}^{*} \vDash_{[y]} \mathrm{A}$. By I. H., $\mathfrak{M} \vDash_{\mathrm{y}} \mathrm{A}$. From truth definition $\mathfrak{M}_{\neq_{\mathrm{y}}} \neg \mathrm{A}$. The definition of $\subseteq{ }^{*}$ shows that $\mathfrak{M}_{\neq_{\mathrm{x}}} \neg \mathrm{A}$. But this contradicts our assumption.

For $\square$ A, suppose that $\mathfrak{M}^{*} \vDash_{[x]} \square$ A but $\mathfrak{M}_{F_{\mathrm{x}}} \square \mathrm{A}$. Since $\mathfrak{M}^{*} \vDash_{[\mathrm{x}]} \mathrm{A}$, $[\mathrm{x}]$ is in $\mathrm{N}^{*}$. By the definition of $\mathrm{N}^{*}$, there exists a formula $\square \mathrm{B}$ in $\Phi$ such that $\mathfrak{M} \vDash \vDash_{\Upsilon} \square \mathrm{B}$. Thus $\mathrm{x}$ is in $\mathrm{N}$. The assumption $\mathfrak{M}_{F_{\mathrm{x}}} \square \mathrm{A}$ indicates that there are $\mathrm{y} \subseteq \mathrm{x}$ and $\mathrm{z}$ such that $\mathrm{yRz}$ and $\mathfrak{M} \neq{ }_{\mathrm{z}} \mathrm{A}$. Clearly yRz and I. H. imply $\mathfrak{M}^{*} \not_{[z]} \mathrm{A}$. Thus we have $\mathfrak{M}^{*} \forall_{[\mathrm{x}]} \square \mathrm{A}$. This contradicts our assumption.

Conversely, suppose that $\mathfrak{M} \models_{\mathrm{x}} \square$ A but $\mathfrak{M}^{*} \forall_{[\mathrm{x} x} \square$ A. By the definition of $\mathrm{N}^{*},[\mathrm{x}]$ is in $\mathrm{N}^{*}$. Since $\left.\mathfrak{M}^{*}\right|_{[\mathrm{x}]} \square \mathrm{A}$ and $[\mathrm{x}] \in \mathrm{N}^{*}$, there are $[\mathrm{y}] \subseteq^{*}[\mathrm{x}]$ and $[\mathrm{z}]$ such that $[\mathrm{y}] \mathrm{R}^{*}[\mathrm{z}]$ and $\mathfrak{M}^{*} F_{[\mathrm{z}]} \mathrm{A}$. We have $\mathfrak{M}_{F} \mathrm{~A}$ by $\mathrm{I}$. H.. The definitions of $\subseteq^{*}$ and of $\mathrm{R}^{*}$ imply $\mathfrak{M}_{\neq_{\mathrm{x}}} \square \mathrm{A}$, but this is a contradiction.

This lemma is completely proved.

From this lemma we can prove that the IE-system has the finite model property.

Theorem 8. The IE-system has the finite model property.

Proof. If $\forall_{\mathrm{IE}} \mathrm{A}$, then we have $\mathfrak{M}_{H_{\mathrm{x}} \mathrm{A}} \mathrm{A}$ for a counter IE-model $\mathfrak{M}$ and an $\mathrm{x} \in \mathrm{W}$. Let $\Phi$ be the set of all subformulas of $\mathrm{A}$. Let 
$\mathfrak{M}^{*}$ be the filtration of $\mathfrak{M}$ through $\Phi$. Since $\Phi$ is finite, $\mathfrak{M}^{*}$ is a finite model. Then by lemma 7 we have $\left.\mathfrak{M}^{*}\right|_{[x]} \mathrm{A}$. This means that the IE-system has the finite model property.

For the IE2-system, we have to check that the filtration $\mathfrak{M}^{*}$ of $\mathfrak{M}$ through $\Phi$ satisfies the frame condition (IE2) when $\mathfrak{M}$ is a model for IE2. This is clear.

Hence we have:

Theorem 9. The IE2-system has the finite model property.

As for the IET-system, we have to change the definition of $\mathrm{R}^{*}$. The new definition is as follows: For $[\mathrm{x}],[\mathrm{y}] \in \mathrm{W}^{*}$,

$[\mathrm{x}] \mathrm{R}^{\prime}[\mathrm{y}]$ iff if $\mathfrak{M} \vDash_{\mathrm{x}} \square \mathrm{A}$ then $\mathfrak{M} \vDash_{\mathrm{y}} \square \mathrm{A}$ for every formula of the form $\square \mathrm{A}$ in $\Phi$.

This definition of $\mathrm{R}^{\prime}$ is well-defined and satisfies the frame condition (IET). By simple calculus, $\mathfrak{M}^{\prime}=\left\langle\mathrm{W}^{*}, \mathrm{~N}^{*}, \subseteq *, \mathrm{R}^{\prime}, \mathrm{V}^{*}\right\rangle$ will be an IET-model.

In order to show that $\mathfrak{M}^{\prime}$ satisfies lemma 7 instead of $\mathfrak{M}^{*}$, we have to indicate that lemma 7 as to IET holds for the case of $\square \mathrm{A} \in$ $\Phi$.

For $\square$ A, suppose that $\mathfrak{M}^{\prime} \vDash_{[x]} \square$ A but $\mathfrak{M}_{F_{\mathrm{x}}} \square \mathrm{A}$. Since $\mathrm{x}$ is in $\mathrm{N}$, there are $\mathrm{y} \subseteq \mathrm{x}$ and $\mathrm{z}$ such that $\mathrm{yRz}$ and $\mathfrak{M}_{H_{\mathrm{z}} \mathrm{A}} \mathrm{A}$. By I. $\mathrm{H}$. we have $\left.\mathfrak{M}^{\prime}\right|_{[z]} \mathrm{A}$. The definitions of $\mathrm{R}^{\prime}$ and of $\subseteq^{*}$ indicate $\left.\mathfrak{M}^{\prime}\right|_{[\mathrm{x}]} \square$ A. But this contradicts our assumption.

Conversely, suppose that $\mathfrak{M}_{F_{\mathrm{x}}} \square$ A but $\mathfrak{M}^{\prime} F_{[\mathrm{x} x} \square$ A. Since $[\mathrm{x}]$ is in $\mathrm{N}^{*}$, there are $[\mathrm{y}] \subseteq^{*}[\mathrm{x}]$ and $[\mathrm{z}]$ such that $[\mathrm{y}] \mathrm{R}^{\prime}[\mathrm{z}]$ and $\mathfrak{M}^{\prime} \not F_{[z]} \mathrm{A}$.

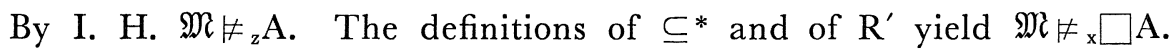
This contradicts our assumption.

Therefore lemma 7 as to IET also holds for $\mathfrak{M}^{\prime}$.

Hence we have:

Theorem 10. The IET-system has the finite model property.

As for the IE4-system, we take $R^{\prime}$ instead of $R^{*}$. It is easy to show that $\mathfrak{M}^{\prime}=\left\langle\mathrm{W}^{*}, \mathrm{~N}^{*}, \subseteq^{*}, \mathrm{R}^{\prime}, \mathrm{V}^{*}\right\rangle$ is an IE4-model when $\mathfrak{M}=$ $\langle\mathrm{W}, \mathrm{N}, \subseteq, \mathrm{R}, \mathrm{V}\rangle$ is one.

Lemma 7 as to IE4 holds for $\mathfrak{M}^{\prime}$. 
Thus we have:

Theorem 11. The IE4-system has the finite model property'.

Unfortunately, I can not say at present whether IE3 has the finite model property.

\section{References}

[1] Chellas, B. F. and McKinney, A., The completeness of monotonic modal logics, Zeitschr. f. Math. Logic und Grundlagen d. Math., 21 (1975), 379-383.

[2] Gabbay, D. M., Decidability results in non-classical logics part I, Ann. Math. Logic, 8 (1975), 237-295.

[3] Goble, G. F., A simplified semantics for modal logic, Notre Dame Jour. Formal Logic, 14 (1973), 151-174.

[4] Humberstone, I. L., From worlds to possibilities, Jour. Phil. Logic, 10 (1981), 313339.

[5] - Interval semantics for tense logic, some remarks, Jour. Phil. Logic, 8 (1979), 171-196.

[6] Kripke, S. A., Semantical analysis of intuitionistic logics I, in: Formal systems and recursire functions, North-Holland, Amsterdam, 1965.

[7] Semantical analysis of modal logic II, in : The theory of models, North-Holland, Amsterdam, 1965.

[8] Röper, P., Interval and tenses, Jour. Phil. Logic, 9 (1980), 451-469.

[9] Thomason, R. H., On the strong semantical completeness of the intuitionistic predicate calculus, Jour. Symb. Logic, 33 (1968), 1-7. 
